\title{
A Study on Relationship between Dermatoglyphics and Hypertension
}

\author{
Arista Lahiri $^{1}$, Soumyajyoti Bandyopadhyay ${ }^{2}$, Shouvanik Adhya ${ }^{2}$, \\ Somanjana Ghosh ${ }^{3}$, Subarna Goswami ${ }^{4}$, Partha Bhattacharya ${ }^{5}$ \\ ${ }^{\prime}$ (Internee, R.G. Kar Medical College \& Hospital, Kolkata, West Bengal, India) \\ ${ }^{2}$ (Department of Forensic Medicine, College of Medicine \& JNM Hospital, WBUHS, Kalyani, West Bengal, India) \\ ${ }^{3}$ (Department of Microbiology, Midnapur Medical College, Midnapur, West Bengal, India) \\ ${ }^{4}$ (ACMOH, Swasthya Bhawan, Saltlake, Kolkata, West Bengal, India) \\ ${ }^{5}$ (Department of Forensic Medicine, RGKarMedical College \& Hospital, Kolkata, West Bengal, India)
}

\begin{abstract}
This study was carried out to determine relationship of palmar dermatoglyphics with the incidence of Hypertension, especially the essential variety. Digital \& palmar dermatoglyphic analysis of 145 normotensive subjects \& 131hypertensive subjects was performed. The parameters used were digital ridge pattern, total ridge count \& atd angle. The result showed that the double loop whorl patterns are present with higher frequency in hypertensives. Total ridge count is significantly higher in hypertensive population $(p<0.05)$. The palm angle (atd angle) has increased value in hypertensive individuals $(p<0.05)$. By this study association of specific dermatoglyphic parameters with the disease mentioned can be established.
\end{abstract}

Keywords - atd angle, Dermatoglyphics, Hypertension, TRC

\section{INTRODUCTION}

Essential hypertension is the category of hypertension that has no identifiable cause. It affects $90-95 \%$ of hypertensive patients. It is also associated with ageing \& inherited genetic factors. Positive family history enhances the risk. Dermatoglyphics, the study of specific patterns of epidermal ridges in the palms \& soles, is an unique \& stable marker of identity, established in utero. Development of those ridges is regulated by genetic \& environmental influences. As there is increased risk of hypertension in individuals with family history because of genetic factors, the study of co-relation between dermatoglyphics and hypertension can help in early identification of people with the genetic predisposition to develop essential hypertension. ${ }^{[1]}$

There are specific patterns of epidermal ridges on finger tip - Loop (Ulnar loop has open end of the loop towards ulnar side \& Radial loop has open end towards the radial side), Whorl (Ridges are Circular), Double Loop Whorl, Arches (Ridges enter from one side make a rise in the center \& exit through opposite side).

A triradius is the meeting point of 3 ridges at a point. Now from this point, a straight line is drawn to the core of the specific pattern. The ridges that cut this line are counted. This number is the total ridge count $(\mathrm{TRC})^{[2]}$ (Fig. 2) for that particular finger. Then average of all ten TRCs in an impression is calculated.

Another parameter of this study, the atd angle is commonly termed as the palm angle. Now for the measurement of the atd angle a formula is used. This formula helps to compute the corrected atd angle. The method of its measurement is as follows:

This atd triangle is formed by joining 3 triradii in the palm. The triradii a $\& \mathrm{~d}$ are respectively at the base of the index \& little fingers. "t" is the axial triradius situated further below (Fig. 1). So the atd angle is formed at the "t" triradius. So at first all the 3 angles are calculated, then corrected atd angle is determined by the formula ${ }^{[3]}$,

$\tan \left(\frac{\text { corrected atd angle }}{2}\right)=\frac{\sin (\text { measured atd angle })}{2 \times \sin (\text { dat angle }) \times \sin (\text { adt angle })}$.

In a study done by Palyzova D et al $(1991)^{[4]}$, conducted in juvenile hypertensive patients had a somewhat lower frequency of fingertip ulnar loops, higher frequency of whorls, higher TFRC and higher mean atd angle. Another study (1989) ${ }^{[5]}$ demonstrated both fingertip whorls and narrow palmar angle are associated with high blood pressure in adult life. Kulkarni DU, Herekar NG (2005) ${ }^{[6]}$ studied that hypertensive patients had a somewhat lower frequency of fingertip ulnar loops, higher frequency of whorls and higher TFRC \& also a somewhat higher mean atd angle.

The present study was carried out to determine correlation of palmar dermatoglyphics with the incidence of Hypertension, especially the essential variety. 3 


\section{MATERIALS AND MethodS}

This particular study is an observational cross sectional study. It has been conducted upon human subjects who gave their consent for being included in this study.

The human subjects are divided in two disjoint groups primarily \& mainly depending upon whether they are hypertensive or not. The hypertensive subjects in this study are those already diagnosed as hypertensive by their physicians. Some of them are even on anti-hypertensive medications as well.

The Hypertensive Individuals are known cases of hypertension. 131 cases are included in this study. The inclusion criteria are presence of hypertension, family history of hypertension. The Normal (Non-Hypertensive) individuals are all normotensives. 145 cases are included. The inclusion criteria are normal blood pressure (i.e. never diagnosed as hypertensive) \& absence of family history of hypertension. Individuals of both the group should have monthly income above Rs. $25000, \&$ their age should be 20 years or more.

Individuals having diabetes mellitus or having family history of diabetes mellitus, or suffering from any skin disease like eczema, leprosy etc involving finger/palm or having scar, congenital \& acquired anomalies of fingers/palm are excluded from both the group. No emphasis was given on gender during sampling.

All the subjects were asked for giving their palmer dermatoglyphic impression on plain white paper using the black ink method. In this method there is a board on which black ink is rolled to make a thin film of ink by a hand roller. The person then firmly presses his palm \& fingers on the board \& then on the white paper so that an impression of his palmer ridges \& patterns can be documented on the sheet for further analysis. This black ink on the palm can easily be washed off with water.

Data collection was done within the period of October, 2012 to April, 2013 in various places of West Bengal (Kolkata, Dumdum, Barrackpore, Serampore). Palm angles are measured using NIST biometric image software ${ }^{[7]}$ SPSS software was used for statistical analysis of the data.

\section{RESULTS}

In case of the hypertensive individuals, incidence of double loop whorl pattern \& arch are $4.57 \%$ \& $5.79 \%$ respectively but those are just $0.44 \% \& 1.33 \%$ in normotensives. Though the differences of incidences of whorl as well as ulnar loop between two groups are not so evident, but still statistically significant $(p<0.05)$. The incidences of specific patterns in the hypertensive $\&$ the normotensive population are shown in Table 1.

The total ridge count clearly stated that it is grossly elevated in case of the hypertensive population compared to the normotensive population. Here in Table 2 the different values of Average Total Ridge Count of hypertensive \& normotensive individuals are shown with their corresponding frequency.

After computing the corrected atd angle, an average of the atd angles of the two hands is made. Table 3 shows mean value, maximum \& minimum values and mode value of corrected atd angle (average of both hand considered) in hypertensive group \& normotensive group.

The overall trend of this parameter is best understood by statistical analysis ( $t$ test) of total series of data which shows differences in values of atd angles of hypertensive \& normotensive group are of statistical significance $(\mathrm{p}<0.05)$.

\section{DISCUSSION}

From Table 1, it is observed that the percentage incidence of Arch and also Double Loop Whorl pattern is clearly higher in hypertensive group. The Radial Loop pattern is however significantly less in incidence in hypertensive group. In both groups of study population, incidence of ulnar loop is higher than that of whorl. The results from a study on hypertensive in Lahore, demonstrated that the hypertensive subjects had a significantly higher frequency of whorl digital pattern $(67 \%)$ than the loop pattern $(28 \%) \cdot{ }^{[8]}$ A study from Nigeria ${ }^{[9]}$ also demonstrated high incidence of whorl pattern are associated with essential hypertension. So our present study does not corroborate with the findings of those studies. This may be due to ethnic or racial variation.

Table 2 demonstrates the grossly elevated average Total Ridge Count in hypertensives. In a study conducted in Department of Pediatrics, School of Medicine, Charles University, Prague, CSFR in 1991 it was found that hypertensive patients had a somewhat lower frequency of fingertip ulnar loops, higher frequency whorls, a higher total finger ridge count, also a somewhat higher mean atd angle. Our present study corroborated with the findings TRC \& atd angle of the study in Prague ${ }^{[4]}$. Study from Nigeria ${ }^{[9]}$ also demonstrated higher digital ridge count in patient with essential hypertension than normotensives.

Finally Table 3 presents the comparison of the corrected atd angle. Considering the central tendencies of the corrected atd angles in the study population, it is higher in the hypertensives. Study from Nigeria ${ }^{[9]}$ found no significant difference in mean atd angles of hypertensive \& normotensive group $(\mathrm{p}>0.05)$. 


\section{TABLES \& FIGURES}

Table 1: Incidence (average of ten fingers) of specific fingerprint patterns in hypertensive group ( $\mathrm{n}=131) \&$ normotensive group $(\mathrm{n}=145)$

\begin{tabular}{|l|l|l|l|l|l|l|}
\hline Group & Whorl & Ulnar Loop & Radial Loop & Double Loop Whorl & Arch & Total (n) \\
\hline Hypertensive & $46(34.06 \%)$ & $67(50.3 \%)$ & $3(1.75 \%)$ & $6(4.57 \%)$ & $9(5.79 \%)$ & 131 \\
\hline Normotensive & $57(39.52 \%)$ & $76(52.34 \%)$ & $9(6.22 \%)$ & $1(0.44 \%)$ & $2(1.33 \%)$ & 145 \\
\hline
\end{tabular}

Chi square value 12.09, Degree of freedom 4, P value 0.016. Differences in percentage frequencies distribution of digital patterns observed between hypertensive \& normotensive subjects are statistically significant.

Table 2: Incidence (average of ten fingers) of total ridge count in hypertensive group ( $\mathrm{n}=131) \&$ normotensive group $(\mathrm{n}=145)$

\begin{tabular}{|l|l|l|}
\hline No. of ridges (Average of ten fingers) & Normotensive group $(\mathrm{n}=145)$ & Hypertensive group (n=131) \\
\hline Less than 5 & $48(33 \%)$ & $7(5 \%)$ \\
\hline 5 to 10 & $36(25 \%)$ & $20(16 \%)$ \\
\hline 11 to 15 & $29(20 \%)$ & $34(26 \%)$ \\
\hline 16 to 20 & $32(22 \%)$ & $63(48 \%)$ \\
\hline More than 20 & $0(0 \%)$ & $7(5 \%)$ \\
\hline
\end{tabular}

Chi square value 52.072, Degree of freedom 4, $\mathrm{P}$ value 0.000

Total ridge count is significantly higher in hypertensive population.

Table 3: Corrected atd angle (average of both hand considered) in hypertensive group $(\mathrm{n}=131)$ \& normotensive group $(\mathrm{n}=145)$

\begin{tabular}{|l|l|l|}
\hline & atd angle in hypertensive group $(\mathrm{n}=131)$ & atd angle in normotensive group $(\mathrm{n}=145)$ \\
\hline Average & $44.27^{\circ}$ & $42.3^{\circ}$ \\
\hline Maximum & $80.15^{\circ}$ & $56.29^{\circ}$ \\
\hline Minimum & $29.2^{\circ}$ & $31.42^{\circ}$ \\
\hline Mode & $40.75^{\circ}$ & Not Available \\
\hline
\end{tabular}

T test value $12.6228, \mathrm{P}$ value 0.000

Differences in values of atd angles of hypertensive \& normotensive group are of high statistical significance.

Figure 1: atd angle ${ }^{[10]}$

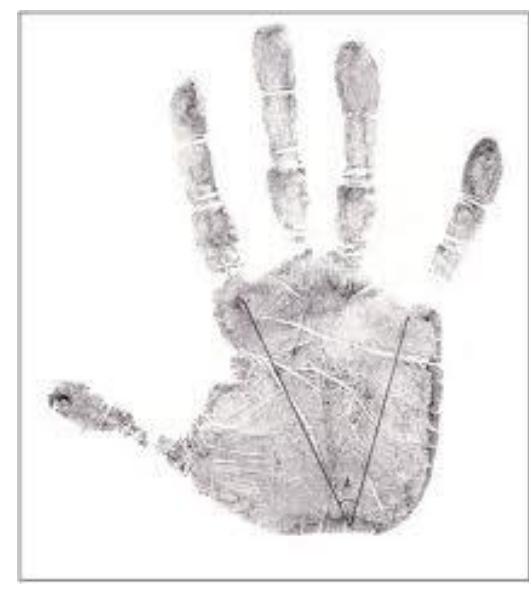

Figure 2: Total ridge count ${ }^{[11]}$

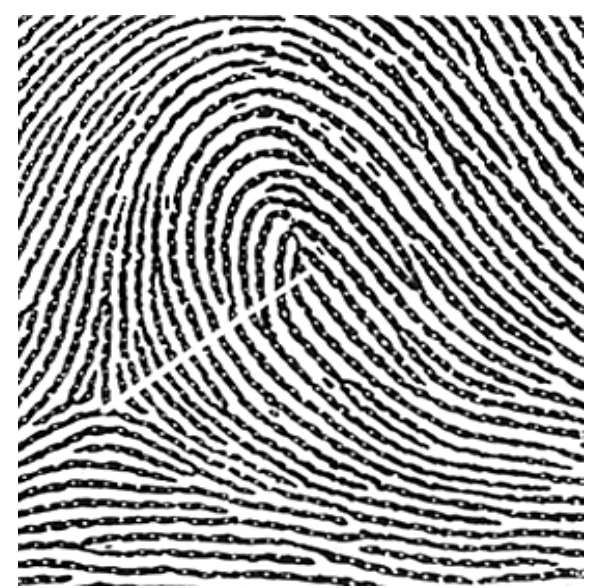

\section{CONCLUSION}

It is evident from the results that arch, double loop whorl, \& radial loop patterns have more incidences with hypertensive population. Total ridge count is more with hypertensive population compared to normal people. The palm angle is also more in persons with high blood pressure. These findings can be used in early detection of essential hypertension in society. Similar studies can be conducted on larger sample size of different population groups to generate more accurate $\&$ comprehensive data. 


\section{ACKNOWLEDGEMENT}

We are indebted to Dr. Ritesh Singh, Assistant Professor, Department of Community Medicine, College of Medicine and JNM Hospital , WBUHS, Kalyani, Nadia for immense help in statistical analysis and interpretation of the data.

\section{REFERENCES}

[1] Deepa.G., Khan A.A.,Study of Palmar Dermatoglyphics in Essential Hypertension among people living in catchment area of NMCH, Raichur.2009. www.rguhs.ac.in/cdc/onlinecdc/uploads/01_M031_10410.doc cited on 12-05-13

[2] Mendenhall G, Mertens T, Hendrix J. Fingerprint Ridge Count- A polygenic trait useful in classroom instruction. The American Biology Teacher, Volume 51, No.4, April 1989, pg 203-207.

[3] David, T.J.(1971). The palmat axial triradius t- a new method of location, Hum.Hered.21:624-627

[4] Palyzová D, Kuklík M, Beránková M, Schaumann B Dermatoglyphics in juvenile hypertension. Department of Pediatrics, School of Medicine, Charles University, Prague, CSFR. 1991

[5] Pursnani ML, Elthence GP, Tiberwala L. Palmar dermatoglyphics in essential hypertension. Indian Heart Journal. 1989; 41(2): 119-122.

[6] Kulkarni DU, Herekan NG. Dermatoglyphics in essential hypertension in Western Maharashtra Population. Journal of natomical Society of India. 2005-06; 54(2):1

[7] http://www.nist.gov/itl/iad/ig/nbis.cfm

[8] Iqbal P et al. Dermatoglyphics Pattern in Hypertensive Patients, http://pjmhsonline.com/OctDec2012/dermatoglyphics_pattern_in_hypertensive\%20pts.htm

[9] Oladipo, G.S, Osogba, I.G, Bobmanuel, I, Ugboma, H.A.A, Sapira, M.K, Ekeke, O.N. Palmer Dermatoglyphics in essential hypertension among Rivers Indigenes. Australian Journal of Basic \& Applied Sciences, 4(12):6300-6305, 2010.

[10] M. Vashist, R. Yadav, . Neelkamal, A. kumar: Axial triradius as a preliminary diagnostic tool in patients of mental retardation. The Internet Journal of Biological Anthropology. 2010 Volume 4 Number 1. DOI: 10.5580/5f8 - See more at: http://archive.ispub.com/journal/the-internet-journal-of-biological-anthropology/volume-4-number-1/axial-triradius-as-a-preliminarydiagnostic-tool-in-patients-of-mental-retardation.html\#sthash.khdgkfI1.dpuf

[11] Exhibit: Measurement of fingerprint ridge count (Kimura 1999, Figure 12.2 p. 167) [m13006.gif], http://www.unc.edu/ nielsen/soci708/m13/m13.htm , cited on 09-06-2013 